\title{
DESAIN PONDASI DENGAN MENGGUNAKAN BATU KALI PADA JALAN SEKAYU-BETUNG
}

\author{
Zuul Fitriana Umari ${ }^{1}$, Bahder Djohan ${ }^{2}$, Andri Subaktio ${ }^{3}$ \\ Email :zuulfitrianaumari@gmail.com
}

\begin{abstract}
Abstrak
Tanah merupakan aspek penting dalam perencanaan konstruksi, oleh karena itu daya dukung tanah merupakan faktor yang menentukan kestabilan, kelayakan dan umur suatu konstruksi.Perencanaan tembok penahan tanah ini berada pada STA \pm 32 pada jalan Sekayu - Betung di desa Sungai Guci Kab Musi Banyuasin.Tujuan dari penelitian ini adalah mendapatkan desain pondasi penahan tanah menggunakan batu kali aman sehingga tidak terjadi lagi longsor.Kdalaman fondasi yang akan di analisis yaitu pada kedalaman $-4,60$ meter dari muka jalan existing dengan hasil pungujian Hand Bor mendapat nilai daya dukung tanah sebesar $2,148 \mathrm{~kg} / \mathrm{cm}^{2}$ dan daya dukung perencanaan sebesar 0,86 $\mathrm{kg} / \mathrm{cm}^{2}$. Berdasarkan analisis didapatkan hasil bahwa fondasi dengankedalaman 7 dari muka jalan existing dan pondasi telapak gabungan dengan panjang 100 meter, lebar 4 meter, dan ketebalan 1 meter mampu menahan beban yang direncanakan. Hal ini didasarkan pada pengecekan terhadap stabilitas internaldanstabilitas eksternal yang dilakukan serta semua syarat keamanan telah terpenuhi.
\end{abstract}

Kata Kunci :Tembok penahan, dimensi, tembok penahan tipe grafitasi

\section{PENDAHULUAN}

Tanah merupakan aspek penting dalam perencanaan konstruksi, oleh karena itu daya dukung tanah merupakan faktor yang menentukan kestabilan, kelayakan dan umur suatu konstruksi.

Beberapa teknik pengendalian tanahdiantaranya perencanaan dinding penahan tanah sehingga dapat meminimalisir terhadap dampak yang timbul terutama pada daerah pemukiman dengan kondisi tanah yang berbeda ketinggian antara titik satu dengan yang lain.Tipe konstruksi yang sering digunakan untuk menahan tanah dibelakangnya dan juga menjaga perbedaan beda tinggi permukaan tanah adalah konstruksi dinding penahan tanah. Dinding penahan tanah adalah konstruksi yang digunakaan untuk memberikan stabilitas tanah pada lereng yang memiliki kemiringan lebih terjal dari kemiringan alaminya agar tidak longsor akibat beban-beban yang bekerja.

Dalam membangun tembok penahan tanah, hal-hal yang perlu diperhatikan adalah :

1. Kestabilan tembok terhadap bahaya guling.

2. Kestabilan tembok terhadap bahaya geser.

3. Kestabilan tembok terhadap bahaya patah.
4. Kestabilan tembok terhadap daya dukung (Amblas).

Semua hal yang dikemukakan diatas harus dihitung satu persatu guna memastikan keamanan bangunan jalan dikemudian hari.

Permasalahan yang ingin diangkat pada kasus ini adalah :

1. Bagaimana desain pondasi penahan tanah menggunakan batu kali yang aman sehingga tidak terjadi lagi longsor pada jalan Sekayu Betung?

2. Bagaimana desain batu kali terhadap gaya yang terjadi pada lereng jalan yang mengalami kerusakan?

Sehingga tujuan dari penelitian ini adalah :

1. Mendapatkan desain pondasi penahan tanah menggunakan batu kali aman sehingga tidak terjadi lagi longgsor pada jalan Sekayu-Betung.

2. Mengetahui desain batu kali terhadap gaya yang terjadi pada lereng jalan yang mengalami kerusakan. 


\section{TINJAUAN PUSTAKA}

a. Dinding penahan tanah

Dinding penahan tanah atau juga biasa disebut tembok penahan adalah suatu konstruksi yang dibangun untuk menahan tanah atau mencegah keruntuhan tanah yang curam atau lereng yang dibangun di tempat, kemantapannya tidak dapat dijamin oleh lereng tanah itu sendiri, serta untuk mendapatkan bidang yang tegak. Bangunan dinding penahan tanah digunakan untuk menahan tekanan tanah lateral yang ditimbulkan oleh tanah urugan atau tanah asli yang labil. Hal ini dipengaruhi oleh kondisi gambaran topografi tempat itu bila dilakukan pekerjaan tanah seperti penanggulan atau pemotongan tanah.

\section{b. Dinding Penahan Tanah Tipe Gravitasi}

Dinding gravitasi adalah dinding penahan yang dibuat dari beton tak bertulang atau pasangan batu.Sedikit tulangan beton kadang-kadang diberikan pada permukaan dinding untuk mencegah retakan permukaan dinding akibat perubahan temperatur (Ir. Sunggono kh,1985).

Pada tembok penahan tipe gravitasi dalam perencanaan harus tidak terjadi tegangan tarik pada setiap irisan badannya.Untuk itu dalam perencanaan tembok penahan jenis ini perlu diperhatikan hal-hal sebagai berikut (lihat gambar1).

- Pada umumnya lebar plat lantai B diambil $0.5-0.7 \mathrm{H}$

- Lebar bagian puncak diambil lebih dari $0.3-\mathrm{H} / 12$

- Tebal kaki dan tumit $(\mathrm{H} / 8-\mathrm{H} / 6)$

- Lebar kaki dan tumit $(0,5-1) \mathrm{d}(\mathrm{d}$ = tebal kaki)

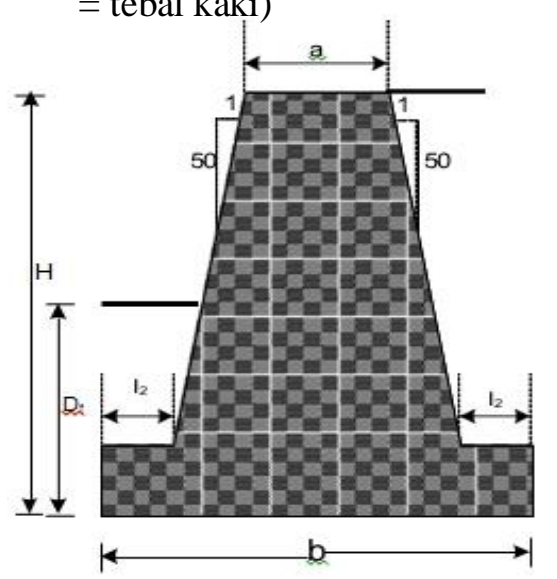

Gambar 1. Dimensi tembok penahan c. TeoriRankine

Teori rankine (1857) dalam hardiyatmo (2006), dalam analisis tekanan lateral dilakukan dengan asumsi-asumsi sebagai berikut :

1) Tanah dalam kedudukan keseimbangan plastis, yaitu sembarang elemen tanah dalam kondisi tepat akan runtuh.

2) Tanah urugan tidak berkohesi $(\mathrm{c}=0)$

3) Gesekan antara dinding dan urugan diabaikan atau permukaan dinding dianggaplicinsempurna $(\delta=0)$

\section{d. Teori Coulomb}

Pada hitungan tekanan tanah lateral teori Coulomb (1776), pengaruh gesekan antara dinding dan tanah urug di belakangnya diperhitungkan. Sudut gesek antara dinding dan tanah $(\delta)$ bergantung pada kekasaran dinding dan regangan lateral pada waktu dindingbergerak.

\section{e. Stabilitas Terhadap Penggeseran}

Faktor aman terhadap penggeseran (Fgs), didefinisikan sebagai:

$$
\mathrm{Fgs}=\frac{\sum R h}{\Sigma P h} \geq 1,5
$$

untuk tanah granular $(\mathrm{c}=0)$

$$
\begin{aligned}
& \sum \mathrm{Rh}=W f \\
& =W t g \delta \mathrm{h}
\end{aligned}
$$

untuk tanah kohesif $(\varnothing=0)$

$\sum \mathrm{Rh}=\mathrm{ca} \mathrm{B}$

Untuk tanah $c-\varnothing(\varnothing>0$ dan $c>0$

$\sum \mathrm{Rh}=c a B+W t g \delta \mathrm{h}$

Dengan :

$\sum \mathrm{Rh}=$ tahanan dinding penahan tanah terhadappenggeseran

$\mathrm{W}=$ berat total dinding penahan dan tanah diatas platfondasi

$\delta \mathrm{h}=$ sudut gesek antara tanah dan dasar 
fondasi, biasanya diambil $(1 / 3-$ $2 / 3) \varnothing$.

$\mathrm{ca}=\mathrm{ad} \times \mathrm{c}=$ adhesi antara tanah dan dasardinding.

Faktor aman terhadap penggeseran dasar fondasi $(F g s)$ minimum, diambil 1,5Bowles(1997) dalam hardiyatmo (2002), menyarankan :

$F g_{S} \geq 1,5$ untuk tanah dasar granular

$F g_{S} \geq 2$ untuk tanah dasar kohesif.

\section{f. Stabilitas Terhadap Penggulingan}

Tekanan tanah lateralyangdiakibatkan oleh tanah urugan dibelakang dinding penahan, cendrung menggulingkan dinding dengan pusat rotasi pada ujung kaki depan fondasi(Cheng Liu, 1981). Momen penggulingan ini, dilawan oleh momen akibat berat sendiri dinding penahan dan momen akibat berat tanah di atas plat fondasi (Gambar 2). Faktor aman terhadap penggulingan $(F g l)$, didefinisikan sebagai:

$$
F g l=\frac{\sum M w}{\sum M g l} \geq 1,5
$$

$$
\begin{aligned}
& \text { Dengan : } \\
& \sum M w=W b 1 \\
& \sum M g l=\sum P a h h l+\sum P a v B \\
& \sum M w=\text { momen yang melawan } \\
& \text { penggulingan (kN.m) } \\
& \sum M g l=\text { momen yang } \\
& \text { mengakibatkan } \\
& \text { penggulingan (kN.m) } \\
& W=\text { berat tanah diatas plat } \\
& \text { fondasi + berat sendiri } \\
& \text { dinding penahan }(\mathrm{kN}) \\
& B=\operatorname{lebar}_{\text {penahan }(\mathrm{m})} \\
& \sum P a h=\text { jumlah gaya- } \\
& \text { gaya horizontal }(\mathrm{kN}) \\
& \sum P a v=\text { jumlah gaya-gaya vertikal } \\
& (\mathrm{kN})
\end{aligned}
$$

Faktor aman terhadap penggulingan $(F g l)$ bergantung pada jenis tanah, yaitu:

- $F g l \geq 1,5$ untuk tanah dasargranular

- $F g l \geq 2$ untuk tanah dasarkohesif.

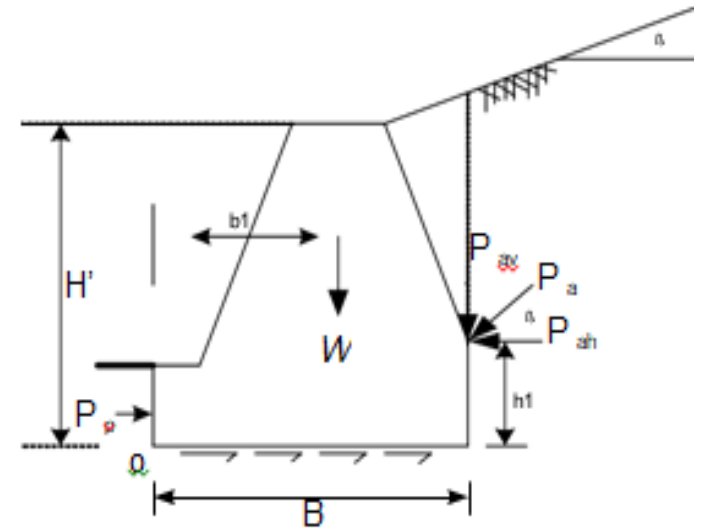

Gambar 2. Stabilitas Terhadap
Penggeseran dan Penggulingan
Sumber : Hardiyatmo, 2002

g. Stabilitas terhadap keruntuhan kapasitas dukungtanah

Kapasitas dukung ultimit dihitung dengan menggunakan persamaan Hansen (1970)dalam Hardiyatmo (2002) untuk beban miring dan eksentris:

$$
\mathrm{qu}=\mathrm{dc} \text { ic } \mathrm{c} \mathrm{Nc}+\mathrm{dq} \text { iq Df } \gamma \mathrm{Nq}+\mathrm{d} \gamma \text { i } \gamma 0,5
$$

$$
\mathrm{B} \gamma \mathrm{N} \gamma
$$

Dengan :

$$
\begin{array}{ll}
\mathrm{dc}, \mathrm{dq}, \mathrm{d} \gamma & =\text { faktor kedalaman } \\
\mathrm{ic}, \mathrm{iq}, \mathrm{i} \gamma & =\text { faktor kemiringan beban } \\
\mathrm{c} & =\text { kohesi tanah }\left(\mathrm{kN} / \mathrm{m}^{2}\right) \\
\text { Df } & =\text { kedalaman fondasi }(\mathrm{m}) \\
\gamma & =\text { berat volume tanah }(\mathrm{kN} / \mathrm{M} 3) \\
\mathrm{B} & =\text { lebar pondasi dindingpenahan } \\
& \operatorname{tanah}(\mathrm{m})
\end{array}
$$

$\mathrm{Nc}, \mathrm{Nqdan} \mathrm{N} \gamma=$ faktor-faktor kapasitas dukung Terzaghi

Faktor aman terhadap keruntuhan kapasitas dukung didefinisikan sebagai :

$$
F=\frac{q u}{q} \geq 3
$$

Dengan $\mathrm{q}=$ tekanan akibat beban struktur. Umumnya, faktor $\operatorname{aman}(F)$ terhadap keruntuhan tanah dasar minimum diambil sama dengan 3.

Bila dihitung dengan berdasarkan lebar fondasi efektif, yaitu tekanan tanah 
fondasi ketanah dasar terbagi rata secara sama, bila:

$\mathrm{e} \leq \mathrm{B} / 6$

$q=\frac{2 V}{s(B-2 e)}$ bila $e \geq B / 6$

Dalam perancangan, lebar fondasi dinding penahan (B)sebaiknya dibuat sedemikian hingga $\mathrm{e}<(\mathrm{B} / 6)$.Hal ini dimaksudkan agar efisiensi fondasi maksimum dan perbedaan tekanan fondasi pada ujungujung kaki dinding tidak besar (untuk mengurangi resiko keruntuhan dinding akibat penggulingan).

\section{Penelitian Terdahulu (Study Desk)}

Adapun beberapa penelitian terdahulu yang dijadikan acuan sebagai bahan pendukung dalam penelitian ini, diantaranya:

1. Sugiyarto

Program Studi Teknik Sipil Universitas Bojonegoro "Perencanaan Pembuatan Tembok Penahan Tanah (TPT) Di desa Napis RT. 04/01 Kecamatan Tambakrejo Kabupaten Bojonegoro" dengan tujuan merencanakan tembok penahan tanah yang meliputi perhitungan setabil terhadap geser, setabil terhadap guling serta control terhadap daya dukung tanah, serta perhitungan tekanan tanah aktif dan pasif.

2. Jurnal Reka Buana Volume 2 No 2, Maret 2017- Agustus 2017

"Perencanaan Dinding Penahan Tanah Pasangan Batu Kali pada Sungai Celaket Desa Gading Kulon Kecamatan Dau Kabupaten Malang"Suhudi, Andreas, Kiki Sulistiani. Program Studi Teknik Sipil, Fakultas Tenik, Universitas Tribuwana Tunggadewi Malang. Dengan tujuan perencanaan dinding penahan tanah (retaining wall) ada tiga prinsip kondisi tanah yaitu, Dalam keadaan diam ( Ko) Keadaaan Aktif ( Ka) Keadaan Pasif ( Kp). Kontrol Stabilitas Perhitungan RAB Perhitungan gempa gambar-gambar Tekanan tanah aktif pada kondisi banjir,
Runtuhya konstruksi akibat daya dukung tanah terlampaui.

Jenis tanah yang ada pada lokasi adalah jenis tanah berpasir, (butiran kasar). Dimensi dinding penahan tanah yang direncanakan pada sungai celaket : Tinggi $(11)=5 \mathrm{~m}$ Lebar $(\mathrm{B})=2,5 \mathrm{~m}$. Lebar atas dinding penahan $=0,4 \mathrm{~m}$ Kedalaman pondasi $=1 \mathrm{~m}$.

\section{Tabel 1. Sistem Klasifikasi Tanah Unified}
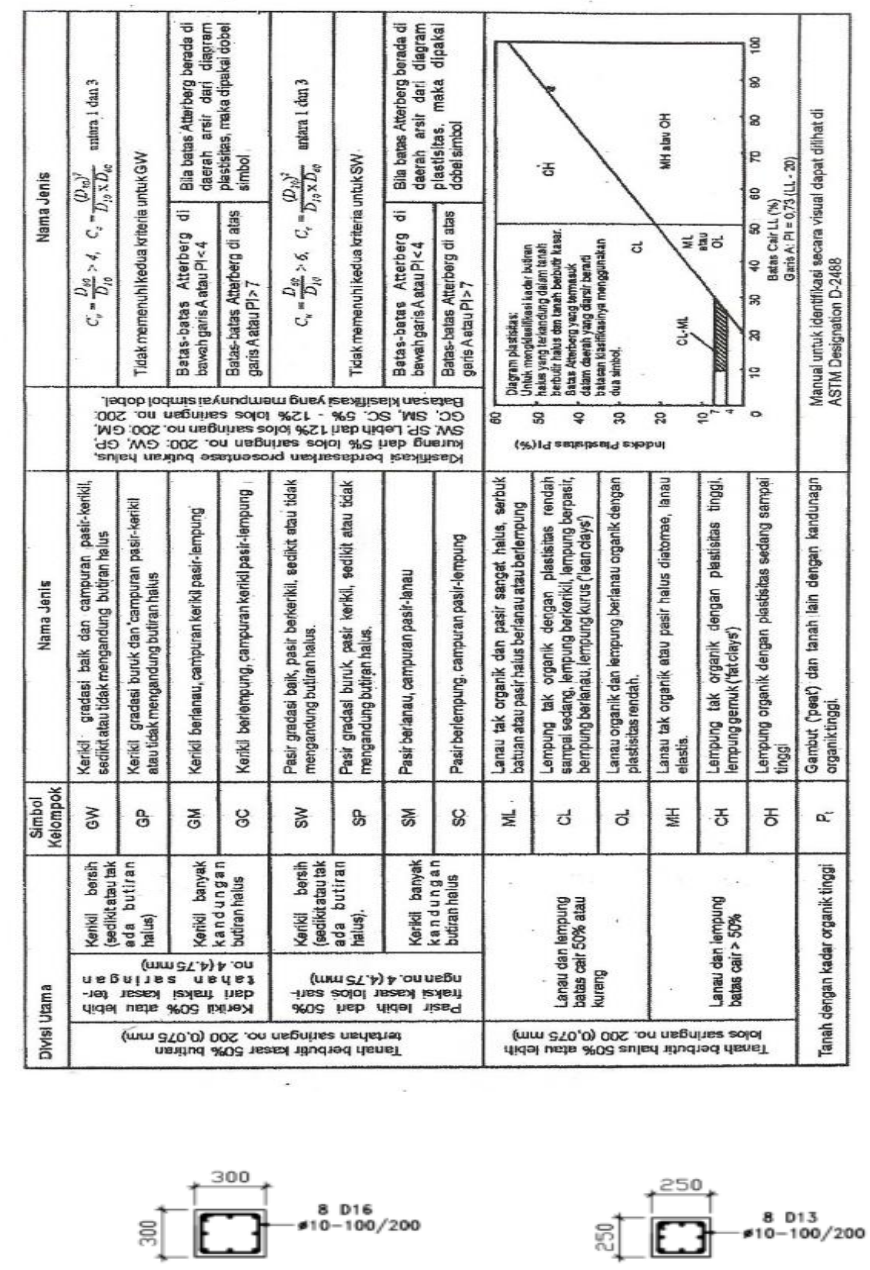

DETAIL KOLOM K1 SKALA $1: 20$ 

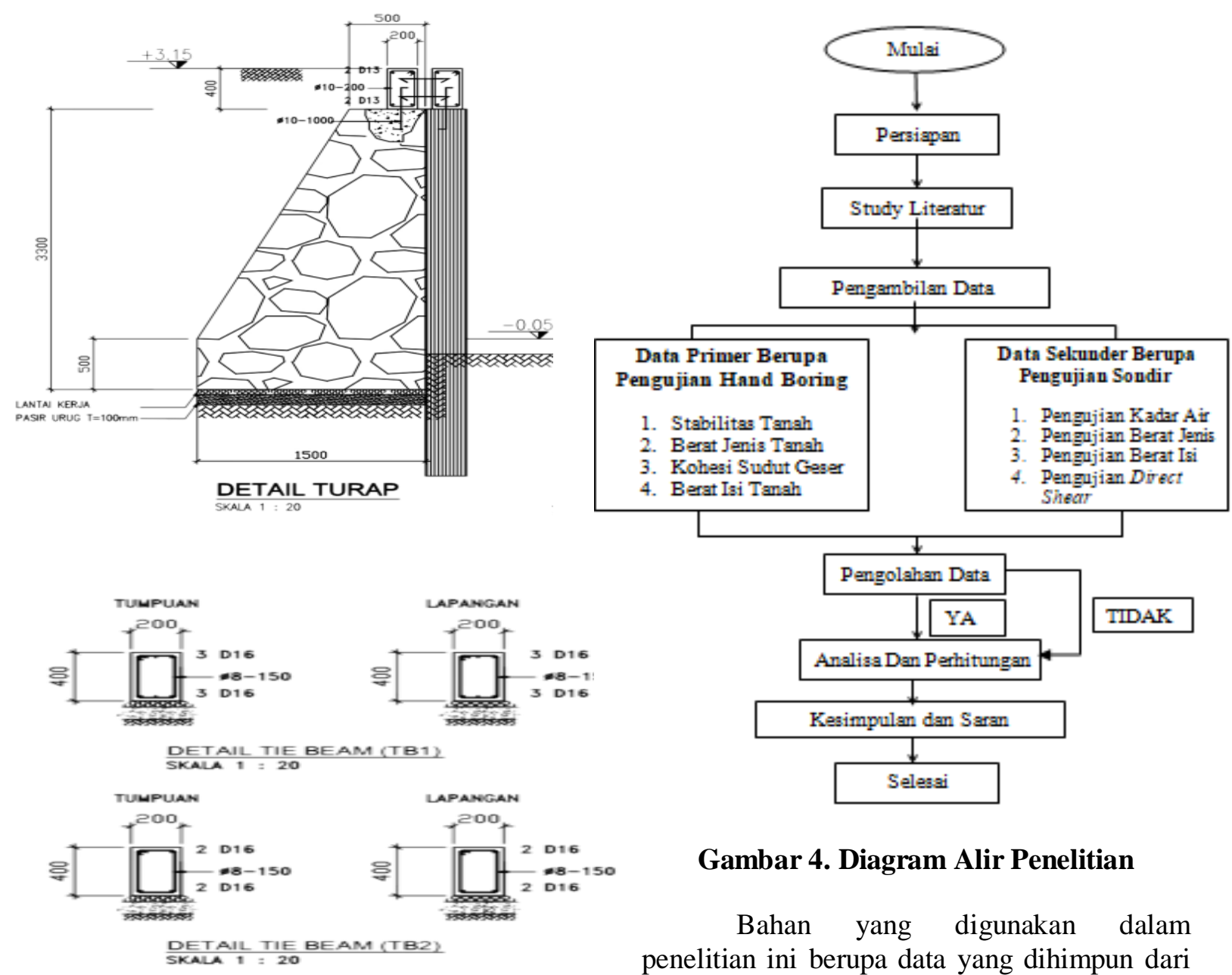

Gambar 3. Rencana Dimensi Pondasi Dinding Penahan Tanah Menggunakan Batu Kali

\section{METODOLOGI PENELITIAN}

Perencanaan tembok penahan tanah ini berada pada STA \pm 32 pada jalan Sekayu Betung di desa Sungai Guci Kab Musi Banyuasin. Yang merupakan akses jalan menuju kabupaten lain seperti Pangkalan Balai.

\section{Diagram Alir Penelitian}

Untuk memberikan kemudahan dalam mencapai tujuan yang diinginkan, perlu dijelaskan mengenai langkah-langkah tahapan pekerjaan mulai dari awal sampai akhir penelitian ini.

\section{Gambar 4. Diagram Alir Penelitian}

Bahan yang digunakan dalam penelitian ini berupa data yang dihimpun dari pengambilan sampel lapangan (Hand Bor, Sondir) dan penelitian laboratorium (kadar air tanah, berat jenis tanah, berat isi tanah dan Direct Shear). Dalam penelitian ini perhitungan secara manual dibantu dengan menggunakan microsoft excel.

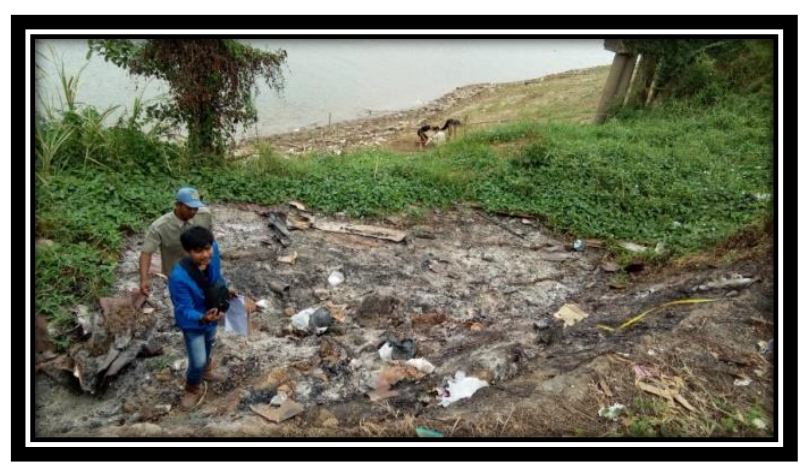

Gambar 5. Peta Loksi Tanah yang Longsor 


\section{Pengujian Laboratorium}

Pekerjaan laboratorium ini bertempat di Laboratorium Di PT. Sucofindo JL.TJ. Apiapi Kebun Bunga Palembang Sumatera Selatan. Pada saat sesudah pengambilan sampel tanah, Hand Boring dengan Sondir .Pengujian yang dilakukan meliputi pengujian fisik tanah dan sifat mekanis tanah.

\section{Pengujian Kadar Air.}

Kegunaan untuk menentukan kadar air tanah yaitu perbandingan berat air yang terkandung dalam tanah dengan berat kering tanah yang dinyatakan dalam persen.

\section{Pengujian Berat Jenis.}

Kegunaan untuk mendapatkan nilai berat jenis suatu tanah.

\section{Pengujian Berat Isi.}

Kegunaan untuk mendapatkan bobot isi (berat isi) tanah yang merupakan perbandingan antara berat tanah basah dengan volumenya dalam $\mathrm{gr} / \mathrm{cm}^{3}$.

\section{Pengujian Direct Shear.}

Kegunaan untuk dapat mengetahui kekuatan tanah terhadap gaya horizontal.

\section{ANALISIS DAN PEMBAHASAN}

Perhitungan Stabilitas Dinding Penahan TipeGravitasi

1. Perencanaan Dimensi Tembok Penahan

Dari pengukuran secara langsung di Sungai guci kedalaman bidang longsor $\left(\mathrm{H}^{\prime}\right)=$ 7 meter. Kedalaman fondasi (D) diambil sebesar 4 meter, sehingga tinggi tembok penahan keseluruhan adalah :

$\begin{array}{lll}\text { BJ Beton } \gamma & =2,4 \mathrm{t} / \mathrm{m} 3 \\ \text { Berat isi tanah } \gamma & =1,438 \mathrm{t} / \mathrm{m} 3 \\ \text { Berat jenis tanahGs }=2, & 63 \\ \text { Kohesi C } & =0,1 \\ \text { Sudut geser } \phi & =18.20^{\circ} \\ \text { Tinggi tembok H } & =7 \mathrm{~m} \\ \text { Tebal kaki d }=\mathrm{H} / 12 & =7 / 12=0,58 \mathrm{~m} \\ \text { Lebar atasa } & =1 \mathrm{~m} \\ \text { Lebar bawah B } & =4 \mathrm{~m}\end{array}$

Untuk hasil analisis stabilitas daya dukung tanah telah dapat di simpulkan, untuk perletakan pondasi adalah $2(\mathrm{dua})$ baris sangat aman untuk dimensi dinding Penahan Tanah tersebut, dan telah ditinjau kembali bahwa terdapat pemborosan dari jumlah tiang pancang dan telah merasiokan atau perbandingan untuk beban Qtembok $: 0,86 \mathrm{~kg} / \mathrm{cm}^{2}<($ lebih kecil dari) beban qultimit : 2,148 ton $/ \mathrm{m}^{2}$.

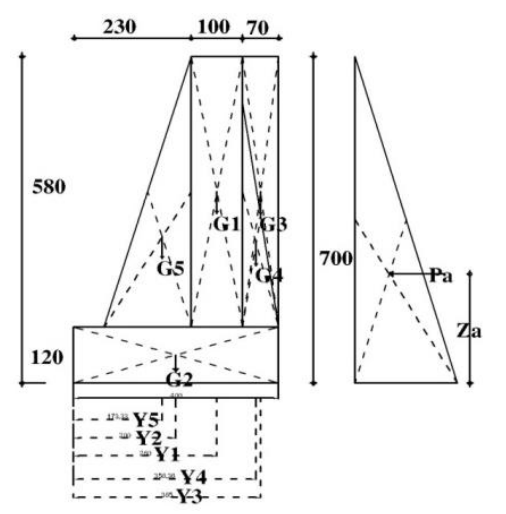

\section{Gambar 6.Pondasi Dinding Penahan Tanah Menggunakan Batu Kali .}

$$
\begin{aligned}
& \mathrm{Y}_{1}=2,3+(1 / 2 * 0,3)=2,45 \mathrm{~m} \\
& \mathrm{Y}_{2}=1 / 2 * 4=2 \mathrm{~m} \\
& \mathrm{Y}_{3}=2,3+0,3+(1 / 2 * 70)=37,6 \mathrm{~m} \\
& \mathrm{Y}_{4}=2,3+0,3+(1 / 3 * 70)=23,6 \mathrm{~m} \\
& \mathrm{Y}_{5}=1 / 2 * 2,3=1,5 \mathrm{~m} \\
& \mathrm{Z} \quad=1 / 3 * \mathrm{H}=1 / 3 * 7=2,33 \mathrm{~m}
\end{aligned}
$$

\section{Berat Sendiri Tembok.}

Untuk berat sendiri tembok dicari dengan mengalikan luas bidang dengan $(\gamma)$ :

$$
\begin{aligned}
& \mathrm{G}_{1}=(0,3 * 5,80) * 2,4 * 1 \mathrm{~m}^{\prime} \quad=4,17 \mathrm{t} / \mathrm{m} \\
& \mathrm{G}_{2}=(1,20 * 4)^{*} 2,4 * 1 \mathrm{~m}^{\prime}=11,52 \mathrm{t} / \mathrm{m} \\
& \mathrm{G}_{3}=\left(0,7 * 5,80 * 2 * 1 \mathrm{~m}^{\prime} \quad=8,12 \mathrm{t} / \mathrm{m}\right. \\
& \mathrm{G}_{4}=(1 / 2 * 0,7 * 4,60 * 0,3) * 2,4 * 1 / 3 \mathrm{~m}^{\prime}=3,47 \mathrm{t} / \mathrm{m} \\
& \mathrm{G}_{5}=(0,7 * 2,42) * 2 * 1 \mathrm{~m}^{\prime} \quad=3,38 \mathrm{t} / \mathrm{m}+ \\
& \mathrm{G}_{\mathrm{tot}}=30,66 \mathrm{t} / \mathrm{m}
\end{aligned}
$$

\section{Koefisien Tekanan Tanah.}

$$
\begin{aligned}
& K a=\cos \beta \frac{\cos \beta-\sqrt{\cos ^{2} \beta-\cos ^{2} \phi}}{\cos \beta+\sqrt{\cos ^{2} \beta-\cos ^{2} \phi}} \\
& K p=\cos \beta \frac{\cos \beta+\sqrt{\cos ^{2} \beta-\cos ^{2} \phi}}{\cos \beta-\sqrt{\cos ^{2} \beta-\cos ^{2} \phi}}
\end{aligned}
$$

$\beta=0$, maka : 


$$
\begin{aligned}
& \mathrm{Ka}=\frac{1-\sin \phi}{1+\sin \phi}=\frac{1-\sin 18^{\circ}}{1+\sin 18^{\circ}}=0,52 \\
& \mathrm{Kp}=\frac{1+\sin \phi}{1-\sin \phi}=\frac{1+\sin 18^{\circ}}{1-\sin 18^{\circ}}=1,91
\end{aligned}
$$

\section{Tekanan Tanah.}

$\mathrm{Pa}$ akibat tanah setinggi 7 meter :

$$
\begin{aligned}
\mathrm{Pa} & =1 / 2 \gamma \mathrm{H}^{2} \mathrm{Ka} \\
& =1 / 2 * 2 *\left(7^{2}\right) * 0,52 \\
& =25,48 \mathrm{t} / \mathrm{m}
\end{aligned}
$$

Pp akibat tanah setinggi 3 meter :

$$
\begin{aligned}
\text { Pp } & =1 / 2 \gamma \mathrm{H}^{2} \mathrm{Kp} \\
\mathrm{Pp} & =1 / 2 * 2 *\left(3^{2}\right) * 1,91 \\
& =17,19 \mathrm{t} / \mathrm{m}^{\prime}
\end{aligned}
$$

\section{Kestabilan Tembok Terhadap Bahaya Guling.}

Syarat Fo $=\frac{\sum M v}{\sum M h} \geq 2,0$

$$
\begin{aligned}
& \begin{aligned}
\Sigma \mathrm{Mv}= & \mathrm{G}_{1} * \mathrm{Y}_{1}+\mathrm{G}_{2} * \mathrm{Y}_{2}+\mathrm{G}_{3} * \mathrm{Y}_{3}+\mathrm{G}_{4} * \mathrm{Y}_{4+} \\
\mathrm{G}_{5} * \mathrm{Y}_{5} & =(15,40 * 1,375)+(5,60 * 2,000)+(19,61 * 2, \\
938 \quad & +(5,03 * 2,583)+(3,04 * 0,438) \\
= & 104,30 \mathrm{tm}
\end{aligned} \\
& \begin{aligned}
\Sigma \mathrm{Mh}= & (\mathrm{Pa} * \mathrm{Za})-(\mathrm{Pp} * \mathrm{Zp}) \\
= & (18,461 * 2,33)-(12,349 * 1) \\
= & 30,73 \mathrm{tm}
\end{aligned} \\
& \begin{aligned}
\mathrm{Fo} \quad= & \frac{104,30}{30,73}=3,39>2
\end{aligned}
\end{aligned}
$$

Jadi tembok aman terhadap bahaya guling.

\section{Kestabilan Tembok Terhadap Bahaya} Geser.

Syarat Fs $=\frac{\sum V^{*} f}{\sum H} \geq 2$

$\Sigma \mathrm{V}=\mathrm{G}_{1}+\mathrm{G}_{2}+\mathrm{G}_{3}+\mathrm{G}_{4}+\mathrm{G}_{5}=48,68 \mathrm{t} / \mathrm{m}^{\prime}$

$$
\begin{aligned}
\Sigma \mathrm{H} & =\mathrm{Pa}-\mathrm{Pp} \\
& =18,461-12,349=6,112 \mathrm{t} / \mathrm{m}
\end{aligned}
$$

$\mathrm{F}=0,75$ (pergeseran tembok dengan beton)

Fs $\quad=\frac{(48,68 * 0,75)}{6,112}=5,9>2$

Jadi tembok aman terhadap bahaya geser.

\section{Kestabilan Tembok Terhadap Bahaya Patah.}



\section{Gambar 7.Potongan A-A Tembok Penahan}

Gaya-gaya yang bekerja pada potongan A-A adalah :

$$
\begin{array}{ll}
\mathrm{G}_{1}=(0,3 * 5,80) * 2,4 * 1 \mathrm{~m}^{\prime} & =4,17 \mathrm{t} / \mathrm{m} \\
\mathrm{G}_{2}=(0,7 * 5,80) * 2 * 1 \mathrm{~m}^{\prime} & =8,12 \mathrm{t} / \mathrm{m} \\
\mathrm{G}_{3}=(0,7 * 2,42) * 2 * 1 \mathrm{~m}^{\prime} & =33,8 \mathrm{t} / \mathrm{m}+ \\
\hline \mathrm{G}_{\mathrm{tot}} & =46,09 \mathrm{t} / \mathrm{m}^{\prime}
\end{array}
$$

Syarat yang harus dipenuhi adalah :

$\tau=\frac{\sum V^{*} f}{\sum H} \geq 2$ (tanah berbutir halus)

$\Sigma \mathrm{V}=38,05 \mathrm{t} / \mathrm{m}^{\prime}$

$\Sigma \mathrm{H}=7,50 \mathrm{t} / \mathrm{m}$

$\mathrm{f}=0,75$ (pergeseran tembok dengan beton)

$$
\tau=\frac{38,05 * 0,75}{7,50}=3,81>2
$$


Jadi tembok aman dari bahaya patah.

\section{Kestabilan Tembok Terhadap Bahaya Amblas.}
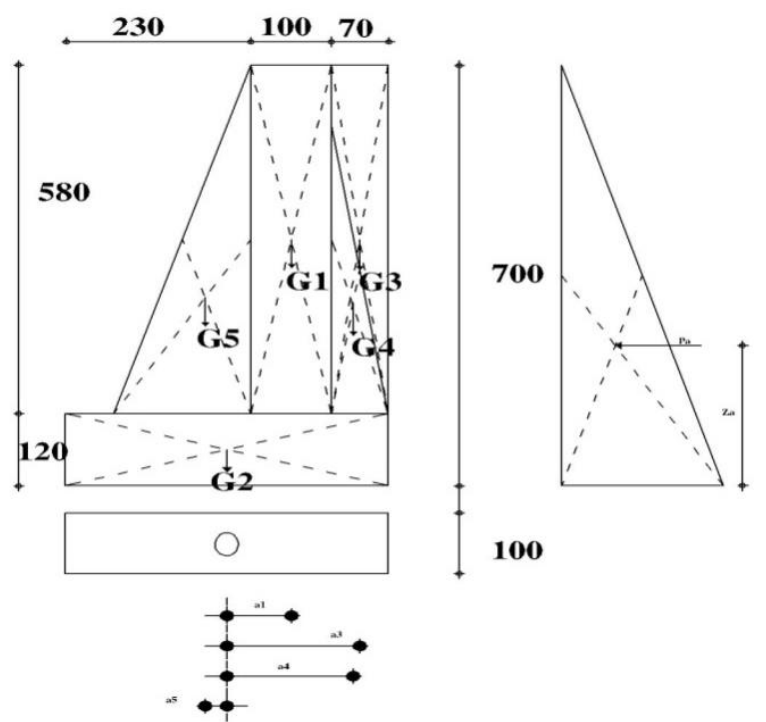

Gambar 8.Kestabilan Tembok

$$
\begin{array}{lc}
\mathrm{a} 1=(1 / 2 * 4)-0,6-(1 / 2 * 0,3) & =1,1 \mathrm{~m} \\
\mathrm{a} 3=(1 / 2 * 4)-(1 / 2 * 0,7) & =1,65 \mathrm{~m} \\
\mathrm{a} 4=(1 / 2 * 4)-(2 / 3 * 0,7) & =1,58 \mathrm{~m} \\
\mathrm{a} 5=(1 / 2 * 4)-(1 / 2 * 0,6) & =1,7 \mathrm{~m} \\
\text { syarat }: \sigma_{12}=\frac{\sum V}{F} \pm \frac{\sum M}{W} \leq \sigma_{g} & \\
\Sigma \mathrm{V} \quad=48,68 \mathrm{t} / \mathrm{m} & =4 * 1=4 \mathrm{~m}^{2} \\
\mathrm{~F} \quad-\left(\mathrm{G}_{1} * \mathrm{a}_{1}\right)+\left(\mathrm{G}_{3} * \mathrm{a}_{3}\right)+\left(\mathrm{G}_{4} * \mathrm{a}_{4}\right)-\left(\mathrm{G}_{5} * \mathrm{a}_{5}\right)-
\end{array}
$$$$
(\mathrm{Pa} * \mathrm{Za})+(\mathrm{Pp} * \mathrm{Zp})
$$$$
=-(4,17 * 1,1)+(33,8 * 1,65)+(3,47
$$$$
* 1,7)-(3,38 * 1,58) \quad-(18,46 * 2,33)
$$$$
+(12,34 * 1)
$$$$
=-21,069 \mathrm{tm}
$$

$$
\begin{aligned}
\mathrm{W} & =1 / 6 * \mathrm{~B} * \mathrm{H}^{2} \\
& =1 / 6 * 1 *\left(4^{2}\right) \\
& =2,667 \mathrm{~m}^{3}
\end{aligned}
$$

$\sigma_{\mathrm{g}}=12-15 \mathrm{~kg} / \mathrm{cm}^{2}$ (tembok batu alam dengan portland cement)

$$
\begin{gathered}
\sigma \quad=\frac{\sum V}{F} \pm \frac{\sum M}{W} \leq \sigma_{g} \\
\sigma_{12}=\frac{48,68}{4} \pm \frac{-21,069}{2,042} \leq \sigma_{g}
\end{gathered}
$$

$\sigma_{1}=11,17-(-10,31)=21,48 \mathrm{t} / \mathrm{m}^{2}=2,148 \mathrm{~kg} / \mathrm{cm}^{2}$ $<\sigma_{\mathrm{g}}$

$\sigma_{2}=11,17+(-10,31)=-86, \quad \mathrm{t} / \mathrm{m}^{2}=-0,86$ $\mathrm{kg} / \mathrm{cm}^{2}<\sigma_{\mathrm{g}}$

Jadi hasil dari perhitungan di dapat,tembok aman dari bahaya amblas di gamabarkan pada gambar berikut ini.



\section{Analisa Hasil Penelitian}

Berdasarkan analisis data yang telah diuraikan di atas, beban izin yang terbesar terjadi pada kombinasi pembebanan yaitu sebesar 25,48 t/m. Beban izin ini merupakan hasil kombinasi dari kombinasi 1 yang berupa beban mati, beban hidup, beban kejut, gaya tekanan tanah, gaya angkat dikombinasikan dengan beban rem, gaya gesek, beban angin, gaya akibat susut dan rangkak, gaya akibat perubahan suhu, dan gaya sentrifugal.

Dalam perhitungan pembebanan ini, peneliti menggunakan data sondir pada pengujian titik ke-2. Pemilihan pada data ini dikarenakan hasil pengujian menyatakan bahwa letak tanah keras berada di kedalaman -11, 20 meter dari muka jalan existing dengan nilai daya dukung tanah sebesar $150 \mathrm{~kg} / \mathrm{cm}^{2}$. Berbeda halnya 
dengan data pengujian sondir pada titik 1 yang menyebutkan bahwa letak tanah keras dengan daya dukung tanah sebesar 120 $\mathrm{kg} / \mathrm{cm}^{2}$ berada di kedalaman $-4,60$ meter dari muka jalanexisting.

Melalui data dari pengujian tanah tersebut, peneliti menentukan kedalaman fondasi yang akan di analisis. Melalui data dari pengujian tanah tersebut, peneliti menentukan kedalaman fondasi yang akan di analisis yaitu pada kedalaman -4,60 meter dari muka jalan existing dengan hasil pungujian Hand Bor mendapat nilai daya dukung tanah sebesar $2,148 \mathrm{~kg} / \mathrm{cm}^{2}$ dan daya dukung perencanaan sebesar 0,86 $\mathrm{kg} / \mathrm{cm}^{2}$.

Berdasarkan analisis didapatkan hasil bahwa fondasi dengankedalaman 7 dari muka jalan existing dan pondasi telapak gabungan dengan panjang 100 meter, lebar 4 meter, dan ketebalan 1 meter mampu menahan beban yang direncanakan. Hal ini didasarkan pada pengecekan terhadap stabilitas internaldanstabilitas eksternal yang dilakukan serta semua syarat keamanan telah terpenuhi.Berikut ini adalah hasil rekapitulasi pengecekan stabilitas internal dan eksternal yang telah di uraikan pada analisis data.

\section{KESIMPULAN DAN SARAN a. Kesimpulan}

Dari hasil dan pembahasan tembokpenahan tanah pada STA \pm 16 Desa Sungai Guci Kabupaten Musi Banyuasin dapat diambilanalisa.

1. Tembok penahan tanah diambil tipe gravitasi berusukdengan tinggi $\mathrm{H}=$ $7 \mathrm{~m}$, tebal dinding atas gravitasi $\mathrm{a}=1 \mathrm{~m}$, lebar tapak fondasi $\mathrm{B}=4 \mathrm{~m}$, tebal tapak0,58 $\mathrm{m}$, serta didapat data-data kestabilan tembok penahan tanah tersebut adalah sebagai berikut :
a. Faktor bahaya Guling didapat sebesar Fo $=3,39 \geq 2$, maka tembok amanterhadap bahaya guling.
b. Faktor bahaya Geser didapat sebesar Fs $=5,97>2$, maka tembok aman terhadapbahaya geser.
c. Faktor bahaya Patah sebesar $\tau=$

3,81> 2, maka tembok aman dari bahayapatah.

d. Dari perhitungan tegangan pada dasar fondasi didapat bahwa daya dukung tanah yang terjadi adalah sebesar $\sigma_{1}$ $=2,148 \mathrm{~kg} / \mathrm{cm}^{2}$ dan $\sigma_{2}=-0,86 \mathrm{~kg} / \mathrm{cm}^{2}$ $<12-15 \mathrm{~kg} / \mathrm{cm}^{2}$, sehingga konstruksi tembok penahan tanah aman terhadap bahaya amblas.

2. Dengan microsoft excel, dapat dicoba/dibuat rancangan untuk berbagai ukuran ketinggian tembok penahan tanah.

\section{b. Saran}

Setelah dilakukan penelitian, maka dapat diberikan saran sebagai berikut :

1. Apabila dalam penelitian ini perhitungan secara manual dibantu dengan menggunakan microsoft excel, maka untuk pengembangan selanjutnya kalau memungkinkan dapat menggunakan software lain sehingga didapat tampilan yang lebih baik.

2. Untuk menghindari terkumpulnya air dibelakang tembok makaharus diberikan saluran air dengan menggunakan pipa yangmenembus tembok penahan tanah.

3. Pada waktu pelaksanaan pembangunan tembokpenahan tanah sebaiknya dilakukan pengawasan yang baik agar maksud perencanaan dapat tercapai sesuai dengan yang diharapkan.

\section{DAFTAR PUSTAKA}

Cheng Liu and Jack B. Event, 1981 "Soil And Foundations" Prentice-Hall, Inc., Englewood Cliffs, New Jersey 07632.

Hardiyatmo, H.C., Mekanika Tanah I, Gama Press, Yogyakarta, 2006.

Hardiyatmo, H.C., Teknik Fondasi I, Beta Offset, Yogyakarta, 2002.

Sunggono KH, Ir. 1995, "Buku Teknik Sipil" Penerbit Nova Bandung.

Sugiyarto. 2017. Perencanaan Pembuatan Tembok Penahan Tanah (TP). Jurnal Deteksi. Jurusan Teknik Sipil. Universitas Bojonegoro. Volume 2 Nomor 2.

Suhudi, dkk. 2017. Perncanaan Dinding Penahan Tanah Pasangan Batu Kali pada Sungai Celaket . Jurnal Reka Buana. Universitas TribuwanaTunggadewi. Volume 2 Nomor 2. 